\title{
Hepatic and renal protective effects of quercetin in ferrous sulfate- induced toxicity
}

\author{
Firouzeh Gholampour and Nadimeh Saki \\ Department of Biology, School of Sciences, Shiraz University, Shiraz, Iran
}

\begin{abstract}
Iron is a vitally important element for the maintenance of health in living organisms. But, iron overload can be toxic. This study investigated the protective efficacy of quercetin against ferrous sulfate-induced oxidative stress, hepato- and nephrotoxicity in rats. There were five experimental groups $(n=7)$ : Sham (distilled water, $1 \mathrm{ml} /$ day for 14 days, i.p.), Quer (quercetin, $50 \mathrm{mg} / \mathrm{kg} /$ day for 14 days, i.p. ), DMSO (dimethyl sulfoxide $1 \%, 1 \mathrm{ml}$ i.p.), Fe (ferrous sulfate, $30 \mathrm{mg} / \mathrm{kg} /$ day for 14 days, i.p.), $\mathrm{Fe}+\mathrm{Quer}$ (ferrous sulfate, $30 \mathrm{mg} / \mathrm{kg} /$ day for 14 days; quercetin, $50 \mathrm{mg} / \mathrm{kg} /$ day for 11 days from fourth day of ferrous sulfate injection). Blood, 24-h urine and tissue samples were collected at the end of experiment. Quercetin prevented ferrous sulfate-induced hepatotoxicity and nephrotoxicity as indicated by decreased activities of serum hepatic marker enzymes and decreased serum bilirubin concentration, higher levels of serum triglyceride, cholesterol, glucose, albumin and total protein, as well as higher creatinine clearance and lower fractional excretion of sodium. Besides, quercetin decreased malondialdehyde levels and histological damages in the liver and kidney of Fe group as compared with sham, DMSO and Quer groups. The protective effect of quercetin relies, at least partially, on its antioxidative effect which leads to decreased lipid peroxidation as well as iron-chelating property.
\end{abstract}

Key words: Albumin - Creatinine clearance - Ferrous sulfate - Glucose - Quercetin

\section{Introduction}

Iron, an important element for living cells, exists most commonly in two forms of ferrous $\left(\mathrm{Fe}^{2+}\right)$ and ferric $\left(\mathrm{Fe}^{3+}\right)$ oxidation states (Bresgen and Eckl 2015). This redox reactivity of iron makes it very useful. However, iron can generate free radicals if it is not tightly bound and/or it is present in excess. It is defined that iron is carried to the liver in severe iron overload conditions (Papanastasiou et al. 2000), where it is stored as ferritin, and is not available to participate in Fenton reaction (Anderson and Frazer 2005). Since hepatocytes have more than one route for importing iron, they have high potential for iron-induced oxidative stress (Puntarulo 2005).

One of the limited numbers of routes for iron elimination from the body is through urinary excretion. After glomerular filtration, iron is reabsorbed in the renal tubules (Smith and Thevenod 2009; Thévenod and Wolff 2016). It is evident that iron has a major role in reactive oxygen species (ROS)-

Correspondence to: Firouzeh Gholampour, Department of Biology, School of Sciences, Shiraz University, Shiraz, Iran

E-mail: gholampour@shirazu.ac.ir induced nephrotoxicity (Baliga et al. 1996, 1998a, 1998b; Sudhir and Shah 2001). It has been demonstrated that iron induces inflammation, oxidative stress, and kidney injury (Bishu and Agarwal 2006). Also, the exposure of human renal endothelial and proximal tubular cells to iron results in massive increase in lipid peroxidation (Zager et al. 2002). It is reported that iron induces kidney injury (Kadkhodaeem and Gol 2004; Bishu and Agarwal 2006) and ferrous form of it catalyzes a reaction that leads to formation of hydroxyl $(\cdot \mathrm{OH})$ radical, which is implicated in the renal tubular injury (Madhusudhan and Oberoi 2011). Also, it is well established that iron mediates tissue injury in several models of acute kidney injury induced by hemoglobin and myoglobin (Paller 1988; Baliga et al. 1996), rhabdomyolysis (Zarjou et al. 2013), cisplatin (Baliga et al. 1998a), and ischemia/reperfusion (Paller and Jacob 1994; de Vries et al. 2004).

Quercetin, a polyphenol flavonoid derived from fruits and vegetables, has unique biological actions including antiinflammatory (Rogerio et al. 2007), antioxidant (Gordon and Roedig-Penman 1998), anti-hypercholesterolemic (Li et al. 2009), anti-hyperlipidemic (Juźwiak et al. 2005; Abdel-Raouf et al. 2011), and antitoxic (Rezaei-Sadabady et al. 2016). 
Thus, the current study conducted to evaluate the protective effect of quercetin on ferrous sulfate (FS)-induced toxicity in the liver and kidney of rats. The liver and kidney functional disorders and histopathology were investigated.

\section{Materials and Methods}

\section{Experimental procedure}

Thirty-five male Wistar rats weighing 250-300 g were purchased from Razi institute, Shiraz, Iran. They were caged at $25 \pm 2{ }^{\circ} \mathrm{C}$ with a light/dark cycle which was alternated every 12 hours. The animals had free access to food and water. The Ethics committee of Shiraz University approved the design of the experimental protocols. The animals were cared for in accordance with Guide to the Care and Use of Experimental Animals (Vol. 1, 2nd ed., 1993, available from the Canadian Council on Animal Care). The rats randomly were divided into five groups (7 each): Sham (1 ml distilled water was injected intraperitoneally (i.p.)), DMSO (dimethyl sulfoxide 1\%, $1 \mathrm{ml}$ was given i.p.), Quer (quercetin, $50 \mathrm{mg} / \mathrm{kg}$ /day dissolved in $1 \mathrm{ml}$ 1\% DMSO and was injected i.p. during 14 days), Fe (ferrous sulfate, $30 \mathrm{mg} / \mathrm{kg} /$ day dissolved in $1 \mathrm{ml}$ distilled water and given i.p. during14 days), Fe+Quer (ferrous sulfate, $30 \mathrm{mg} / \mathrm{kg} /$ day during 14 days; quercetin, 50 $\mathrm{mg} / \mathrm{kg} /$ day during 11 days starting 4th day of ferrous sulfate administration). Fourteen days after the beginning of ferrous sulfate/quercetin administration, rats were placed in metabolic cages to collect 24-h urine. At the end of experimental period, rats were anesthetized with ketamine and xylazine (60 and $5 \mathrm{mg} / \mathrm{kg}$, i.p., respectively) and blood samples were taken from heart ventricles. Subsequently, the liver and left kidney were quickly removed. Parts of liver and kidney preserved for future histological examination and the rest was immediately deep frozen until further use.

\section{Renal functional assessments}

Urine samples, collected at the end of the 24-h period, were assayed for creatinine by colorimetric methods (Prestige, Biolis24I, Japan). Also, serum samples were assayed for blood urea nitrogen (BUN) and creatinine by colorimetric methods. To indicate glomerular function, creatinine clearance $\left(\mathrm{C}_{\mathrm{Cr}}\right)$ was calculated using urinary and serum creatinine concentration in conjunction with urine flow. Besides, urinary and serum $\mathrm{Na}^{+}$was measured at the end of the 24 -h period by flame photometry to estimate the fractional excretion of $\mathrm{Na}^{+}\left(\mathrm{FE}_{\mathrm{Na}}\right)$.

\section{Biochemical estimation}

Measurement of serum and tissue levels of aspartate aminotransferase (AST), alanine aminotransferase (ALT), alkaline phosphatase (ALP) and lactate dehydrogenase (LDH) activi- ties were done by commercially available kits. Tissue enzymatic assay was done after homogenizing liver tissue samples in the citrate buffer $(\mathrm{pH} 4.8)$ and centrifuging at $10,000 \times g$ at $4^{\circ} \mathrm{C}$ for 15 minutes. Afterwards the supernatant was removed and stored on ice. The levels of total bilirubin, albumin, total protein, glucose, cholesterol and triglycerides in the serum samples were measured by commercially available kits too.

\section{Lipid peroxidation assay}

Tissue malondialdehyde (MDA) content was assayed in the liver and kidney tissue samples (homogenized in $5 \mathrm{ml}$ of trichloroacetic acid per $0.1 \mathrm{~g}$ of tissue) spectrophotometrically (Heath and Packer 1968). The method is based on MDA reaction with thiobarbituric acid (TBA) that yields pink colored thiobarbituric-MDA adducts. Its absorbance was measured at $532 \mathrm{~nm}$.

\section{Histopathological examinations}

The left kidney and liver samples were removed and fixed in 10\% buffered formaldehyde solution. After dehydration through a graded alcohol series, the samples were cleared in xylol. Then, kidney and liver samples were embedded in paraffin and cut into $5-\mu \mathrm{m}$ thick slices using a microtome (Zeiss, Germany). The slices of liver and kidney were mounted on glass slides and stained with prussian blue as well as hematoxylin and eosin. Each slice was examined in a blinded fashion in more than 10 non-overlapping fields under light microscope. In each liver slice, the degree of the presence of congestion and cellular degenerative changes were examined. Also, in each kidney slice, the degree of tubular necrosis, loss of brush borders, and vascular congestion were examined. The level of pathological changes was graded as follow: none with 0 , less than $20 \%$ with 1 , $21-40 \%$ with $2,41-60 \%$ with $3,61-80 \%$ with 4 , and greater than $80 \%$ with 5 . In each group, the sum of all numerical scores was taken as the total histopathological score.

\section{Statistical analysis}

The data are expressed as mean \pm SEM. The comparison among experimental groups was done by one-way ANOVA followed by post-hoc (Tukey) test using SPSS version 22 software (SPSS Software, Chicago, IL, USA). The significance was considered at $p<0.05$.

\section{Results}

\section{Effect of quercetin on FS-induced changes in body weight}

Figure 1 shows that mean body weight value of Fe group was reduced in comparison to sham, DMSO and Quer groups $(p<$ 
$0.01, p<0.05$ and $p<0.01$, respectively). Body weight value in $\mathrm{Fe}+\mathrm{Quer}$ group was statistically lower than that of sham $(p<$ $0.001)$, DMSO $(p<0.01)$ and Quer $(p<0.001)$ groups, but it showed no significant change in comparison with Fe group.

Quercetin decreases FS-induced changes in the liver functional markers

Figure 2 displays serum levels of hepatic markers in the experimental groups. In the rats treated with FS, AST, ALT, LDH and ALP activities were significantly increased $(p<0.001$, $p<0.05, p<0.001, p<0.001$, respectively). These changes were reversed significantly by quercetin administration $(p<$ $0.05, p<0.05, p<0.001$ for AST, LDH and ALP, respectively).

As presented in Table 1, FS treatment increased serum level of total bilirubin in Fe group compared to those of sham, DMSO and Quer groups $(p<0.001, p<0.01$ and $p<0.001$, respectively). It also displays that FS treatment decreased serum levels of glucose $(p<0.01, p<0.001$ and $p<0.01$ as compared sham, DMSO and Quer groups, respectively),

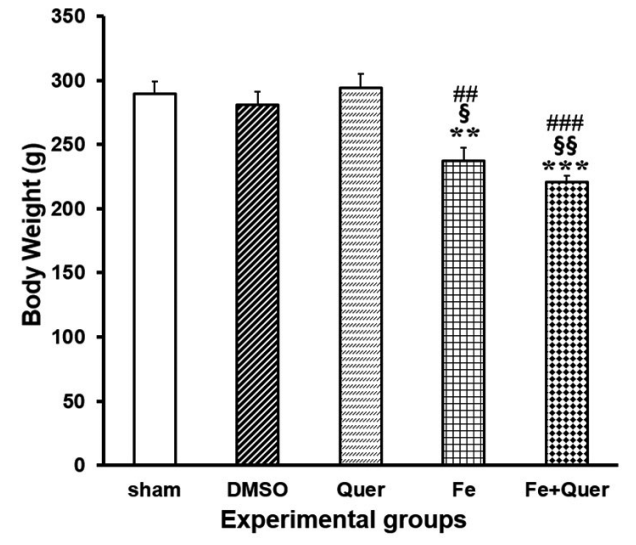

Figure 1. Quercetin (50 mg/kg/day) and ferrous-sulfate $(30 \mathrm{mg} / \mathrm{kg} /$ day)-induced changes of body weight. Data are the mean \pm SEM ( $n=7$ in each group). ${ }^{* *} p<0.01,{ }^{* *} p<0.001$ as compared to the sham group; ${ }^{\S} p<0.05,{ }^{\$ S} p<0.01$ as compared to the DMSO group; \#\# $p<0.01,{ }^{\# \#} p<0.001$ as compared to the Quer group. DMSO, dimethyl sulfoxide; Quer, quercetin; Fe, ferrous sulfate. For more information, see Materials and Methods.
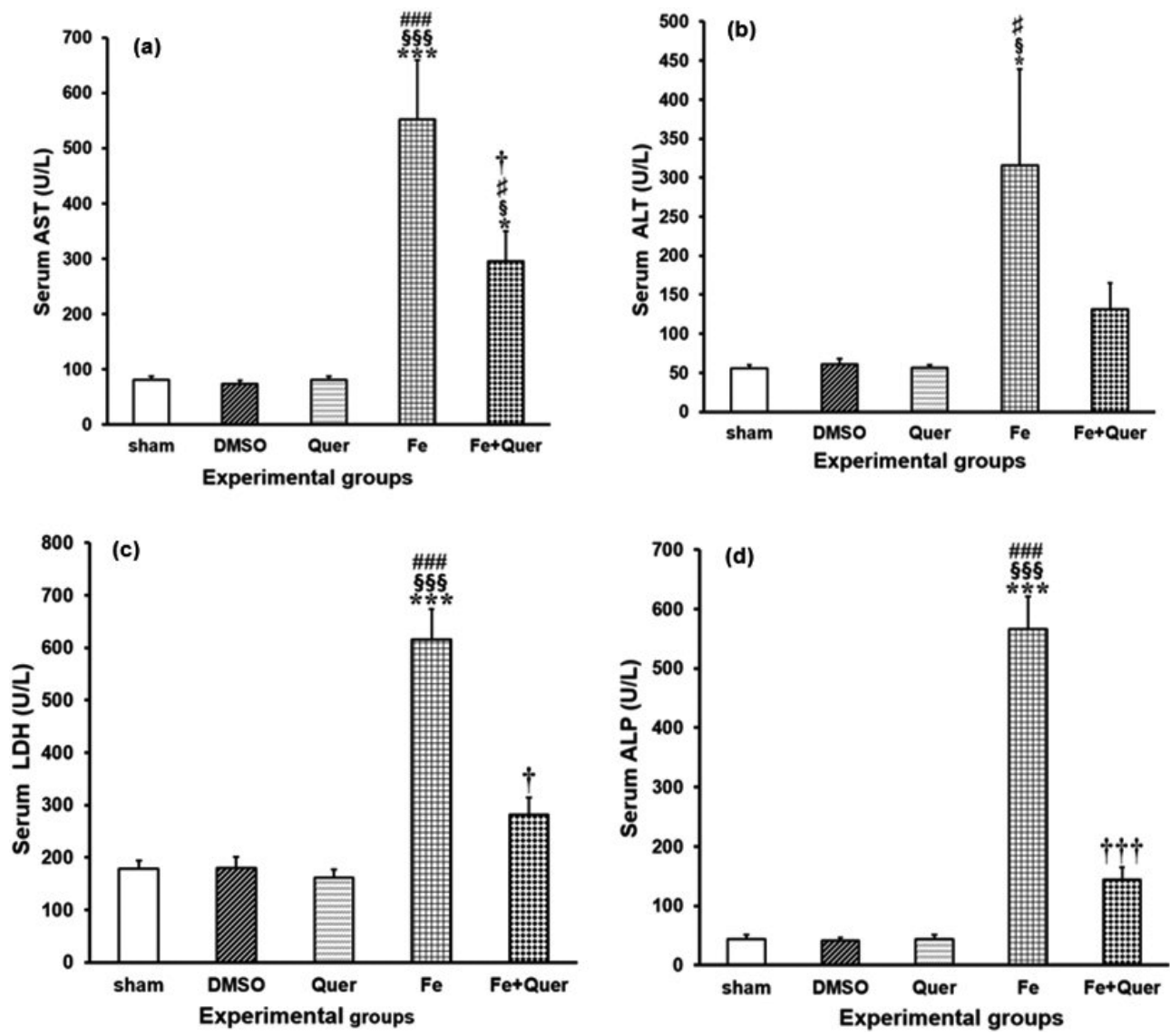

Figure 2. Quercetin and ferrous-sulfate-induced changes in hepatic enzyme activities. Data are the mean \pm SEM ( $n=7$ in each group). ${ }^{\star} p<0.05$, ${ }^{* * *} p<0.001$ as compared to the sham group; ${ }^{\S} p<0.05,{ }^{\$ \subseteq} p<0.001$ as compared to the DMSO group; ${ }^{\#} p<0.05$, \#\#\# $p<$ 0.001 as compared to the Quer group; ${ }^{\dagger} p<0.05,{ }^{\dagger \dagger \dagger} p<0.001$ as compared to the Fe group. AST, aspartate aminotransferase; ALT, alanine aminotransferase; LDH, lactate dehydrogenase; ALP, alkaline phosphatase. For more information, see Materials and Methods. 
triglyceride $(p<0.001, p<0.01$ and $p<0.001$ as compared sham, DMSO and Quer groups, respectively), cholesterol $(p<0.05, p<0.05$ and $p<0.01$ as compared sham, DMSO and Quer groups, respectively), total protein ( $p<0.05$ as compared sham and DMSO groups) and albumin $(p<0.001$, $p<0.01$ and $p<0.001$ as compared sham, DMSO and Quer groups, respectively) in Fe group in comparison to the levels of sham, DMSO and Quer groups. Quercetin injection significantly reversed the changes of triglyceride $(p<0.01)$, glucose $(p<0.01)$ and total bilirubin $(p<0.05)$.

Referring to Table 2, FS treatment raised the activities level of AST, ALT, LDH and ALP in the liver tissue of Fe group compared to those of sham, DMSO and Quer groups $(p<0.001)$. Administration of quercetin lowered the levels of AST, ALT and LDH in Fe+Quer compared to Fe group $(p<0.05)$.

\section{Quercetin decreases FS-induced changes in renal function parameters}

FS treatment induced changes in renal functional markers such as increase $(p<0.001)$ of creatinine, urea nitrogen (Table 3 ) and fractional excretion of $\mathrm{Na}^{+}\left(\mathrm{FE}_{\mathrm{Na}}\right)$ (Fig. 3) as well as decrease $(p<0.001)$ of creatinine clearance (Fig. 3$)$. These

Table 1. Effect of quercetin on ferrous sulfate-induced changes in the levels of serum biochemical parameters in rat

\begin{tabular}{|c|c|c|c|c|c|}
\hline & \multicolumn{5}{|c|}{ Groups } \\
\hline & Sham & DMSO & Quer & $\mathrm{Fe}$ & $\mathrm{Fe}+\mathrm{Quer}$ \\
\hline Total bilirubin (U/l) & $0.70 \pm 0.10$ & $0.64 \pm 0.10$ & $0.62 \pm 0.11$ & 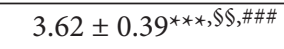 & 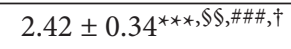 \\
\hline Glucose (mg/dl) & $135.71 \pm 9.45$ & $144.71 \pm 10.65$ & $131.42 \pm 9.08$ & 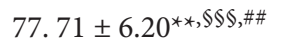 & $138.14 \pm 13.03^{\dagger \dagger}$ \\
\hline Triglyceride (mg/dl) & $91.00 \pm 4.61$ & $70.14 \pm 7.40$ & $84.71 \pm 5.46$ & 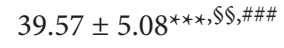 & $75.71 \pm 5.21^{\dagger \dagger}$ \\
\hline Cholesterol (mg/dl) & $55.28 \pm 3.42$ & $55.00 \pm 2.74$ & $59.42 \pm 4.63$ & 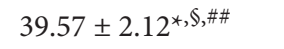 & $54.14 \pm 4.33$ \\
\hline Total protein $(\mathrm{mg} / \mathrm{dl})$ & $6.81 \pm 0.32$ & $6.88 \pm 0.21$ & $6.42 \pm 0.65$ & $5.11 \pm 0.16^{\star, \Im}$ & $6.25 \pm 0.22^{\#}$ \\
\hline $\operatorname{Albumin}(\mathrm{mg} / \mathrm{dl})$ & $3.87 \pm 0.29$ & $3.50 \pm 0.16$ & $3.97 \pm 0.31$ & 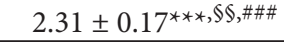 & $3.05 \pm 0.16$ \\
\hline
\end{tabular}

The data are expressed as mean \pm SEM, $n=7$. ${ }^{*} p<0.05,{ }^{* *} p<0.01,{ }^{* * *} p<0.001$ compared to the Sham group; ${ }^{\S} p<0.05,{ }^{\$ \S} p<0.01$, ${ }^{\S S \$} p<0.001$ compared to the DMSO group; ${ }^{\#} p<0.05,{ }^{\# \#} p<0.01,{ }^{\# \# \#} p<0.001$ compared to the Quer group; ${ }^{\dagger} p<0.05,{ }^{\dagger \dagger} p<0.01$ compared to the Fe group. DMSO, dimethyl sulfoxide; Quer, quercetin; Fe, ferrous sulfate. For more information, see Materials and Methods.

Table 2. Effect of quercetin on ferrous sulfate-induced changes in the activities of hepatic and lipid peroxidation markers in liver tissue homogenates in experimental groups

\begin{tabular}{|c|c|c|c|c|c|}
\hline & \multicolumn{5}{|c|}{ Groups } \\
\hline & Sham & DMSO & Quer & FS & FS+Quer \\
\hline $\operatorname{AST}(\mathrm{U} / \mathrm{l})$ & $770.00 \pm 31.48$ & $722.57 \pm 66.98$ & $717.00 \pm 47.46$ & 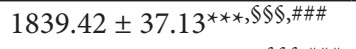 & 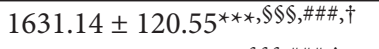 \\
\hline $\operatorname{ALT}(\mathrm{U} / \mathrm{l})$ & $717.14 \pm 56.23$ & $694.85 \pm 17.21$ & $693.14 \pm 62.29$ & 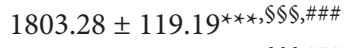 & $1492.14 \pm 39.38^{\star \star \star}, \$ \S \S, \# \# \#, \dagger$ \\
\hline $\mathrm{LDH}(\mathrm{U} / \mathrm{l})$ & $694.00 \pm 50.61$ & $703.85 \pm 44.69$ & $683.14 \pm 49.30$ & 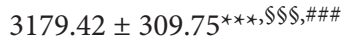 & $2371.00 \pm 196.06^{* * *}, \S \S \S, \# \# \#, \dagger$ \\
\hline $\operatorname{ALP}(\mathrm{U} / \mathrm{l})$ & $693.85 \pm 53.77$ & $704.28 \pm 39.98$ & $664.71 \pm 51.37$ & 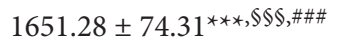 & 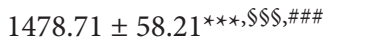 \\
\hline MDA (mol/g tissue) & $0.50 \pm 0.05$ & $0.64 \pm 0.09$ & $0.50 \pm 0.04$ & 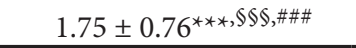 & $1.02 \pm 0.12^{\dagger}$ \\
\hline
\end{tabular}

The data are expressed as mean \pm SEM, $n=7 .{ }^{* * *} p<0.001$ as compared to the Sham group; ${ }^{\$ \$ \$} p<0.001$ as compared to the DMSO group; $\# \#$ \#\# $p .001$ as compared to the Quer group; ${ }^{\dagger} p<0.05$ as compared to the FS group. For more information, see Materials and Methods.

Table 3. Effect of quercetin on the levels of renal function parameters and lipid peroxidation marker in experimental groups

\begin{tabular}{|c|c|c|c|c|c|}
\hline & \multicolumn{5}{|c|}{ Groups } \\
\hline & Sham & DMSO & Quer & $\mathrm{Fe}$ & $\mathrm{Fe}+\mathrm{Quer}$ \\
\hline Creatinine (mg/dl) & $0.45 \pm 0.02$ & $0.48 \pm 0.02$ & $0.50 \pm 0.02$ & 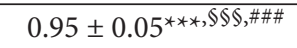 & $0.58 \pm 0.03^{\dagger \dagger \dagger}$ \\
\hline Urea nitrogen $(\mathrm{mg} / \mathrm{dl})$ & $23.14 \pm 1.60$ & $25.14 \pm 1.10$ & $22.71 \pm 1.16$ & 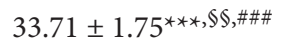 & $25.71 \pm 1.44^{\dagger \dagger}$ \\
\hline MDA (mol/g tissue) & $0.49 \pm 0.04$ & $0.51 \pm 0.03$ & $0.57 \pm 0.06$ & 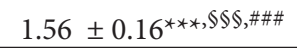 & $0.71 \pm 0.07^{\dagger \dagger \dagger}$ \\
\hline
\end{tabular}

The data are expressed as mean \pm SEM, $n=7 .{ }^{* * *} p<0.001$ compared to the Sham group; ${ }^{\S \S} \mathrm{p}<0.01,{ }^{\$ \S \S} p<0.001$ compared to the DMSO group; ${ }^{\# \#} p<0.001$ compared to the Quer group; ${ }^{\dagger \dagger} p<0.01,{ }^{\dagger \dagger \dagger} p<0.001$ compared to the Fe group. For more information, see Materials and Methods. 


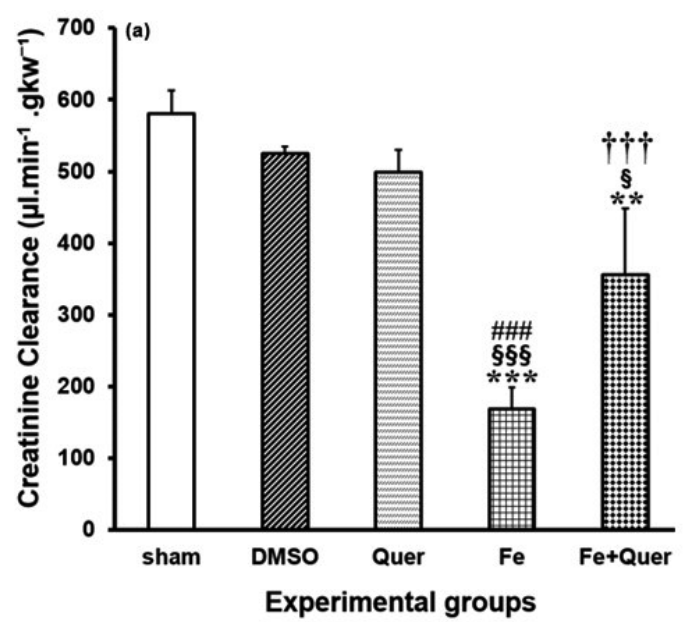

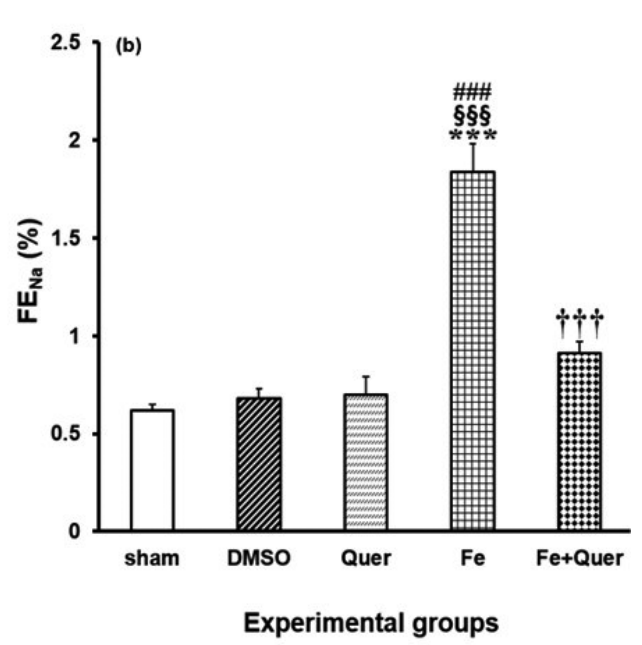

Figure 3. Quercetin and ferrous-sulfate-induced changes in renal function parameters $\left(\mathrm{C}_{\mathrm{Cr}}\right.$ and $\left.\mathrm{FE}_{\mathrm{Na}}\right)$. Data are the mean \pm SEM $(n=7$ in each group). ${ }^{\star *} p<0.01$, ${ }^{* * *} p<0.001$ as compared to the sham group; ${ }^{\S} p<0.05$, $\$ \$ \$<0.001$ as compared to the DMSO group; ${ }^{\# \#} p<$ 0.001 as compared to the Quer group; ${ }^{\dagger \dagger} p<0.001$ as compared to the Fe group. $\mathrm{C}_{\mathrm{Cr}}$, creatinine clearance; $\mathrm{FE}_{\mathrm{Na}}$, fractional excretion of $\mathrm{Na}^{+}$. For more information, see Materials and Methods. changes were reversed by quercetin significantly $(p<0.001$ for all except $p<0.01$ for urea nitrogen).

Effect of quercetin on the hepatic and renal oxidative stress induced by FS

According to Tables 2 and 3 FS treatment led to significant increases in MDA contents of the liver and kidney compared with the sham, DMSO and Quer groups $(p<0.001)$. Quercetin treatment reduced the levels of MDA in the tissue of the liver $(p<0.05)$ and kidney $(p<0.001)$ in Fe+Quer in comparison to Fe group.

\section{Effect of quercetin on the hepatic and renal histological damages induced by FS}

Histological studies of the liver showed no abnormalities or histological changes in the livers of sham, DMSO
(Figures not presented to be more brief) and Quer groups (Figs. 4 and 5). But, iron deposition (grade 2) was seen in the Fe group (Fig. 4). However, iron deposition (grade 1) was decreased in the Fe+Quer group (Fig. 4) compared to Fe group.

The most eminent damages of the Fe group were hepatocellular apoptosis (grade 2, Fig. 5Ca), swelling of the hepatic cells (grade 2, Fig. 5Cb), vacuolization of the hepatocyte cytoplasm (grade 2, Fig. 5Cc) and inflammatory cell infiltration in the portal space (grade 3, Fig. 5Cd). Quercetin treatment reduced the histological damages in the $\mathrm{Fe}+\mathrm{Quer}$ group compared to Fe group (Fig. 5E).

Renal sections from the sham, DMSO (Figures not presented to be more brief) and Quer groups (Figs. 6Aa, b, c, and d) showed no changes. But, iron deposition (grade 2) was noticed in the cortex (Fig. 6Ba) and medulla (Fig. 6Bb) of the Fe group. However, quercetin treatment reduced iron deposition (grade 1) in Fe+Quer group (Fig. 6Ca and b).

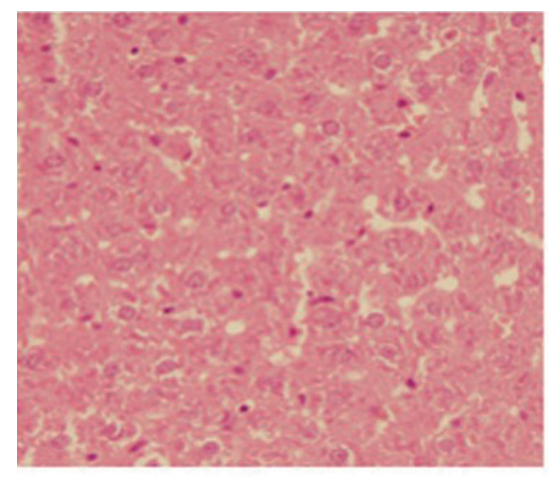

Ouer

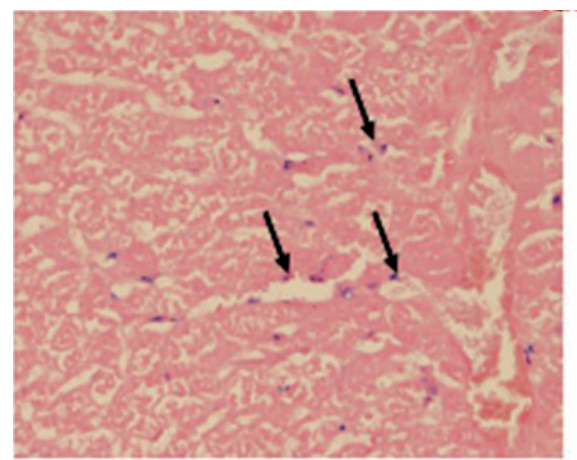

$\mathrm{Fe}$

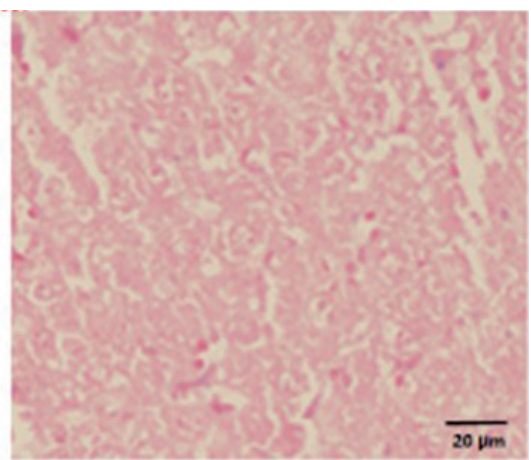

$\mathrm{Fe}+$ Quer

Figure 4. Representative light microphotographs of the livers. Prussian blue-stained slices were assessed under light microscopy. The histological changes observed included iron deposition. Black arrows indicate iron deposition. For more information, see Materials and Methods. 
Besides, congestion (grade 2) was observed in glomerular capillaries (Fig. 6Bc) and medullary vessels (Fig. 6Bd) of the Fe group. However, congestion (grade 1) was reduced in $\mathrm{Fe}+\mathrm{Quer}$ group (Fig. 6Cc and d) compared to Fe group. Table 4 demonstrates the sum of histopathological grades, showing the changes illustrated above.
A

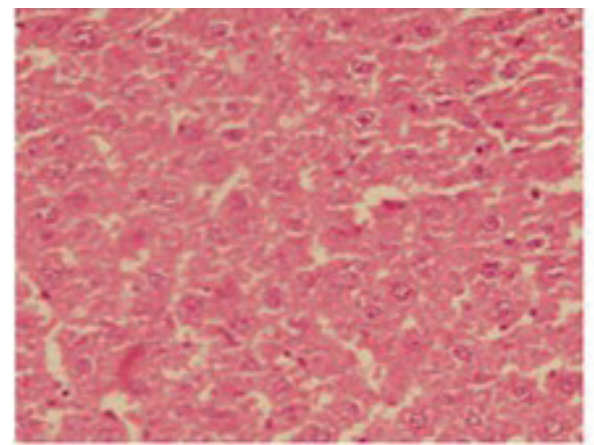

C

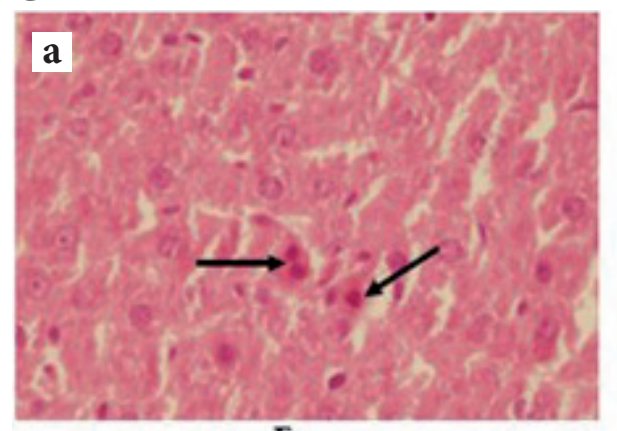

Fe

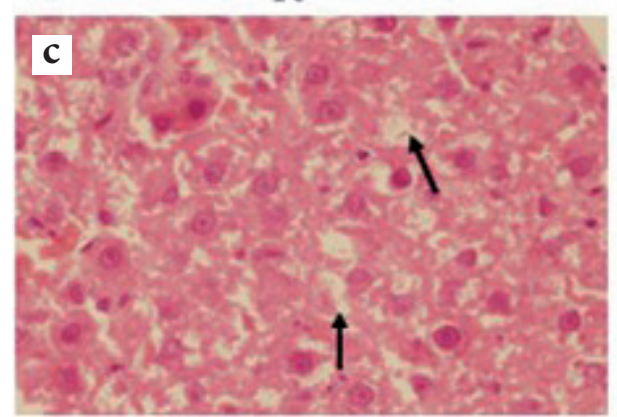

Fe

D

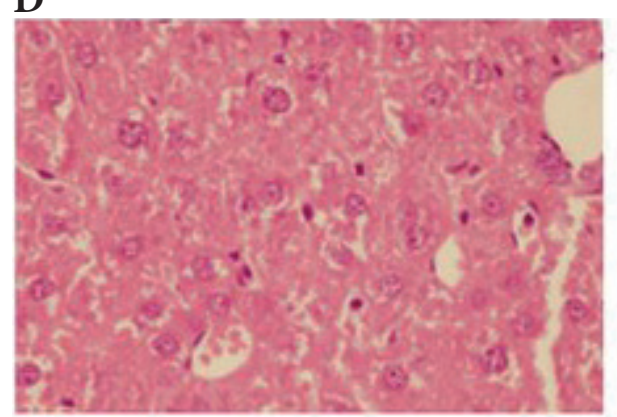

DMSO
B

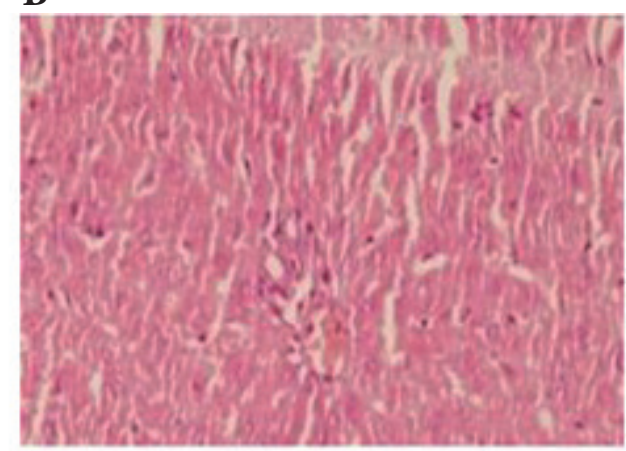

Quer
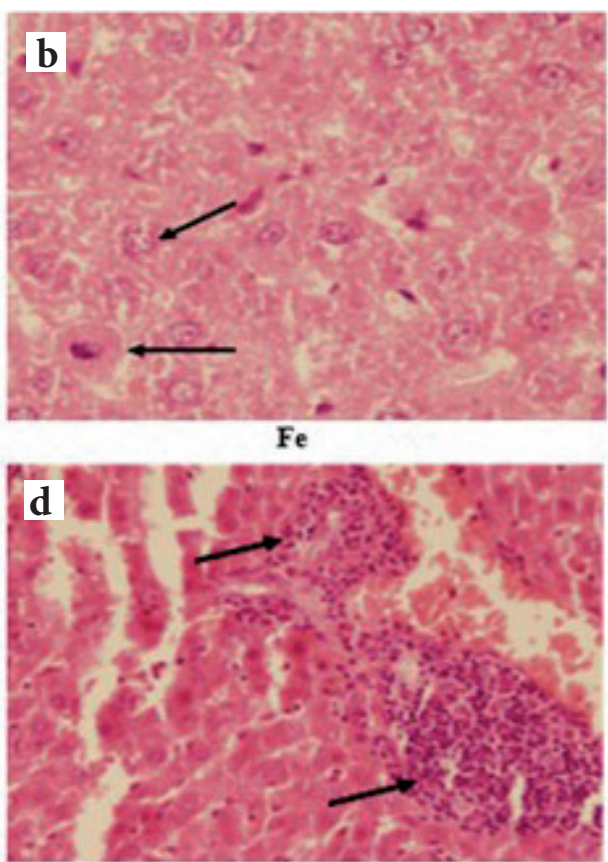

Fe

E

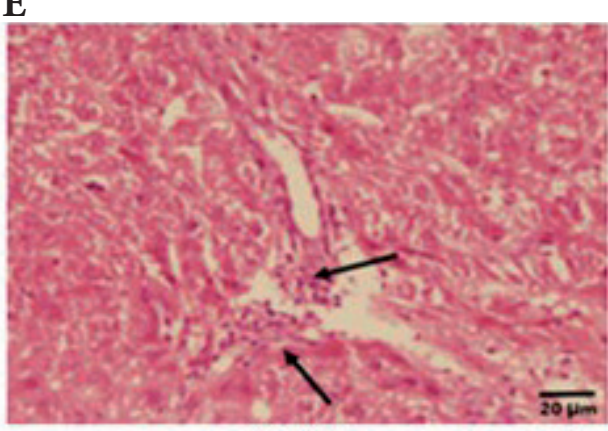

$\mathrm{Fe}+$ Quer
Figure 5. Light micrographs of the livers. Hematoxylin and eosin-stained slices were assessed under light microscopy. A. Sham group. B. Quer group. C. Fe group. Black arrows show apoptosis (a), swelling (b), vacuolization (c), inflammatory cell infiltration (d). D. DMSO group. E. $\mathrm{Fe}+\mathrm{Quer}$ group. For more information, see Materials and Methods. 
A

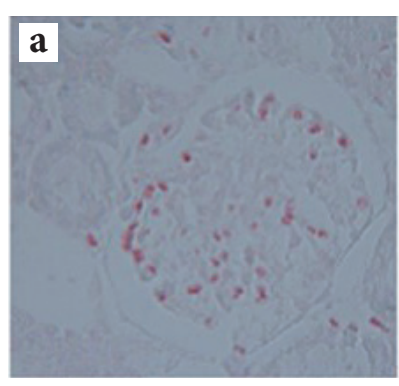

B

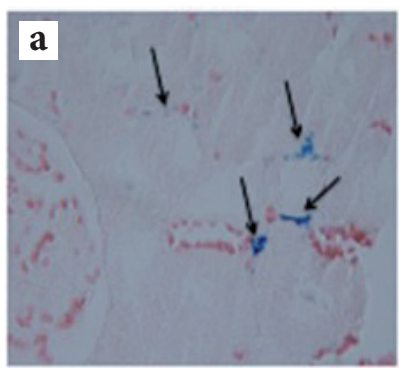

C

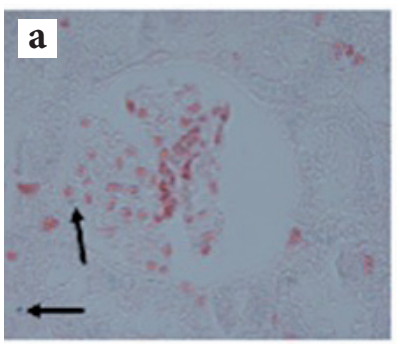

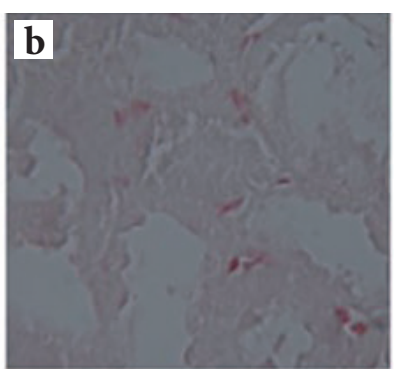
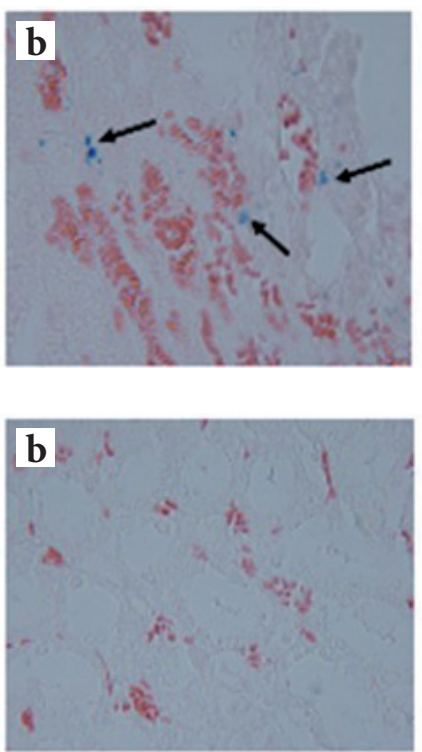
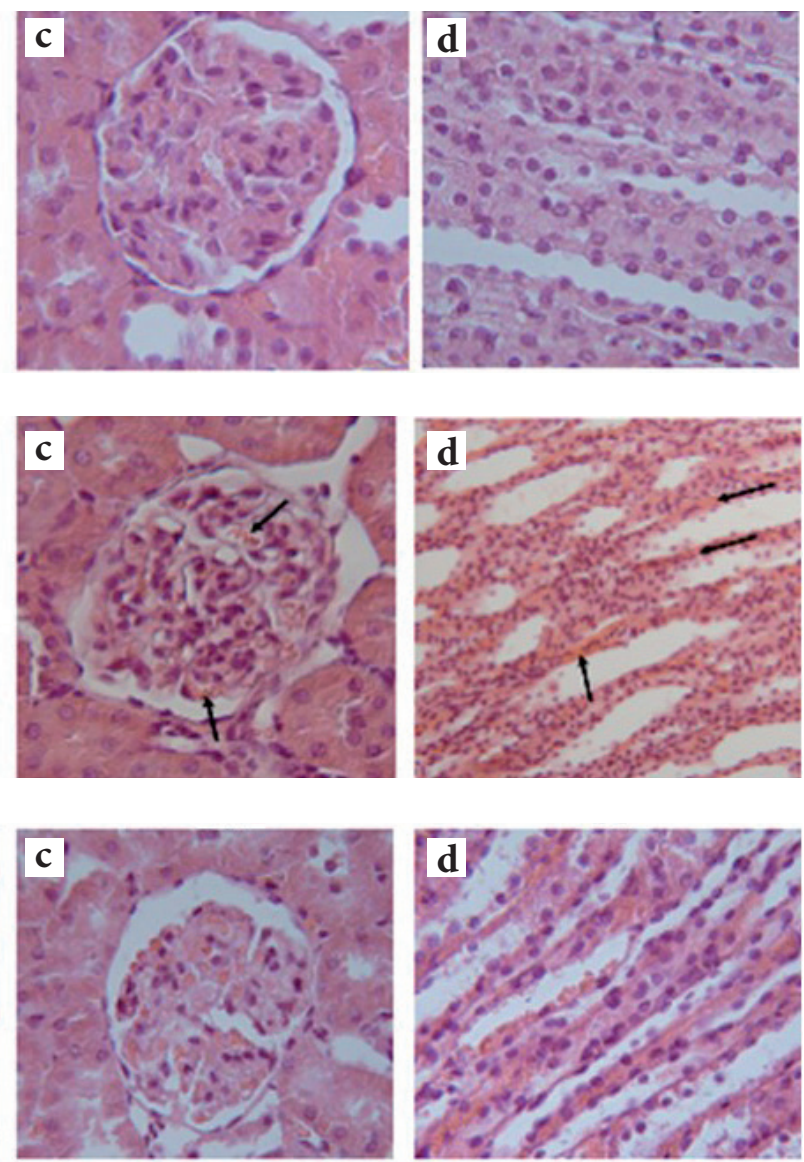

Figure 6. Representative light microphotographs of the kidneys. Prussian blue- and hematoxylin \& eosin-stained slices were assessed under light microscopy (magnification $\times 400$ ). A. Quer group. B. Fe group. C. Fe+Quer group. The histological changes observed included iron deposition in cytoplasm of: cortical (Ba, Ca) and medullary (Bb, Cb) tubular cells, prussian blue staining; glomerular capillary congestion $(\mathrm{Bc}, \mathrm{Cc})$ and medullary vascular congestion $(\mathrm{Bd}, \mathrm{Cd})$, hematoxylin-eosin staining. For more information, see Materials and Methods.

\section{Discussion}

Iron, as an essential element, is used therapeutically in higher doses and in the form of ferrous sulfate (FS) to treat and prevent iron deficiency anemia. In patients with iron deficiency anemia, the rate of iron bioavailability from a therapeutic dose of FS, the most commonly used oral iron preparation, is $\sim 10 \%$ (McDonagh and Macdougall 2015). Once iron deficiency has been diagnosed, for restoration of the iron supply, the daily elemental iron requirement is $10 \mathrm{mg}$ in children, adult males and post- menopausal women (to provide $1 \mathrm{mg}$ to the body), $20 \mathrm{mg}$ in young non-pregnant women and $30 \mathrm{mg}$ in pregnant women (Alleyne et al. 2008). The present study demonstrated that FS overload $(30 \mathrm{mg} / \mathrm{kg})$ promotes oxidative stress in the liver and kidney of male rats and thereafter contributes to the functional disorders and histological injuries. Our findings suggest that quercetin $(50 \mathrm{mg} / \mathrm{kg} /$ day $)$ preserved the function and histological pattern of liver and kidney against FS-induced oxidative stress.

Iron accumulation in hepatic parenchymal cells is a well-documented event and is considered as an impor-

Table 4. Total histopathological score in Sham, DMSO, Quer, Fe and $\mathrm{Fe}+\mathrm{Quer}$ groups at the end of the experiment

\begin{tabular}{lcc}
\hline Groups & Liver & Kidney \\
\hline Sham & $0.0 \pm 0.00$ & $0.0 \pm 0.00$ \\
DMSO & $0.0 \pm 0.00$ & $0.0 \pm 0.00$ \\
Quer & $0.0 \pm 0.00$ & $0.0 \pm 0.00$ \\
Fe & $10.25 \pm 0.52^{* * *}$ & $6.75 \pm 0.25^{* * *}$ \\
Fe+Quer & $3.87 \pm 0.29^{* * *, \dagger \dagger \dagger}$ & $2.87 \pm 0.44^{* * *, \dagger \dagger \dagger}$ \\
\hline
\end{tabular}

Values (sum of histopathological scores in each group) are expressed as mean \pm SEM, $n=7$. ${ }^{* * *} p<0.001$ compared to the Sham, DMSO and Quer groups; ${ }^{\dagger \dagger} p<0.001$ compared to the Fe group. For more information, see Materials and Methods. 
tant mechanism of liver damage (Anderson and Frazer 2005). The serum total bilirubin level was increased in the Fe group, which is in line with the result of other investigators who found that iron overloaded hepatic injury leads to enhanced levels of serum total bilirubin (Das et al. 2015). Also, in the present study, FS-induced liver damage was manifested by high activities of hepatic enzymes. Excessive iron deposition in the liver has a major role in triggering the damage because it is involved in the induction of oxidative stress and the increased ROS production (Badria et al. 2015; Idilman et al. 2016). Administration of quercetin (50 mg/ $\mathrm{kg} /$ day for 14 days) significantly protected the liver against iron-induced toxicity in the Fe group and improved in its functional efficiency, as demonstrated by prevention of the increase in serum and liver tissue levels of AST, ALT, LDH, ALP activities, serum level of total bilirubin and liver lipid peroxidation as well as improvement in histology. This could be attributed to the membrane protective effect of quercetin (Vlachodimitropoulou et al. 2011; Bao et al. 2017).

In this work FS treatment lowered serum concentration of glucose. It has been suggested that FS can augment activities of the enzymes involved in glucose metabolism and respiratory chain by increasing the supply of oxygen, and thereby decreases serum glucose levels following accelerating glucose metabolism (Zhang et al. 2008). Besides, this hypoglycemia could be ascribed to impairment in gluconeogenesis. The liver secretes glucose through both gluconeogenesis and glycogenolysis (Rui 2014). Liver glycogen stores are depleted following uncoupling of oxidative phosphorylation because of defective energy-linked mitochondrial function (Nocito et al. 2015). Quercetin treatment, probably through its antioxidative effect, significantly reduced the FS-induced lipid peroxidation in the liver as proved by the decreased levels of MDA. Hence, quercetin raised glucose concentration to the normalcy through its ability to decrease lipid peroxidation. Besides, it has been demonstrated that quercetin induces glycolysis via inhibiting glucose oxidation in mitochondria (Lang and Racker 1974; Gasparin et al. 2003). Protective effect of quercetin on the $\mathrm{Fe}^{2+}$-induced peroxidative damage has been already demonstrated (Boadi et al. 2003). Light microscopy showed that iron accumulation in the liver was effectively diminished by quercetin, which revealed that quercetin chelates the iron (Leopoldini et al. 2006; Mladenka et al. 2011; Vlachodimitropoulou et al. 2011). In this regard, it has been reported that quercetin as an antioxidant (Bao et al. 2017), readily permeates cell membranes (Fiorani et al. 2003) via glucose transport proteins (Strobel et al. 2005; Cunningham et al. 2006) and acts as effective intracellular iron chelator, which can clean the excess iron in the body. Quercetin, as an iron chelator, could suppress iron overloadinduced injury in the liver and kidney of the mouse (Zhang et al. 2011). Amelioration of iron overload-induced liver toxicity by a potent antioxidant and iron chelator has been shown in another study using Emblica officinalis fruit extract (Sarkar et al. 2015).

Apoptosis has an important role in liver pathogenesis. One of the factors which cause a cell undergo apoptosis, is oxidative stress. Oxidative stress is a pathogenic mechanism of hepatic damage. In the present study, apoptosis and leukocyte infiltration were other notable pathological features of FS-induced hepatotoxicity. ROS formation due to iron-induced oxidative stress (Puntarulo 2005) may cause hepatocyte apoptosis and leukocyte infiltration. Quercetin injection decreased the FS-induced histological alterations and restored physiological functions toward normalcy. This finding accords with the results of others who found that quercetin attenuated inflammatory cell infiltrations induced by obesity (Dong et al. 2014) and bile duct obstruction (Lin et al. 2014) in the liver.

Hepatocyte ballooning and cytoplasmic vacuolization, which are frequently seen in acute liver injury, were observed in the Fe group under light microscopy. In the current study, FS treatment caused increment in the serum cholesterol and triglyceride (TG) concentrations in the Fe group. However, quercetin reversed these changes in $\mathrm{Fe}+\mathrm{Quer}$ group. Since the FS-induced increase in serum cholesterol may be owing to changes in the gene expression of liver enzymes chiefly HMG CR (HMG-COA reductase) (Kojima et al. 2004) and HMG CR transcription is controlled by SREBP (sterol regulatory element-binding protein) (Goldstein and Brown 2009), it is suggested that the ability of quercetin to decrease the expression of SREBP-1c and fatty acid synthase (Wang et al. 2015) leads to decrease of serum lipids concentration. In addition, it has been shown that quercetin up-regulates gene expression of low-density lipoprotein receptor (LDLR), which increases LDL cholesterol clearance from the circulation (Moon et al. 2012). Also, quercetin increases the expression of cholesterol 7a-hydroxylase (CYP7A1) (Zhang et al. 2016) ), which is involved in the cholesterol conversion to bile acids (Donepudi et al. 2018). Besides, it has been demonstrated that quercetin inhibits cholesterol and TG synthesis in hepatic cells (Juźwiak et al. 2005; Padma et al. 2012). Taken together, the therapeutic efficacy of quercetin against hyperlipidemia which seen in the current work is probably due to a combined effect of its capability of promoting cholesterol efflux and cholesterol conversion to bile acid (Zhang et al. 2016) as well as its antioxidant capacity (Mariee et al. 2012) .

One of the most important functions of the liver is protein synthesis. FS treatment significantly reduced serum levels of total protein and albumin in the present study. In line with these results, it has been demonstrated that total protein (Pawar et al. 2012) and albumin levels are decreased in FS-induced hepatotoxicity (Abdel-Reheim et al. 2017). Administration of quercetin increased the levels of total protein and albumin, which might be due to the ability of 
quercetin to improve liver function. In accordance with this result, the ameliorative efficacy of quercetin on the altered levels of total protein and albumin toward normalcy has been reported (Singh et al. 2011). Although, the high binding of quercetin to human serum albumin has been demonstrated (Boulton et al. 1998). Quercetin, even though considerably prevented FS-induced decreases in total protein and albumin, failed to prevent the weight loss in rats injected with FS. This may be due to lowering effect of quercetin on the body weight gain (Kobori et al. 2011; Jung et al. 2013; Hoek-van den Hil et al. 2014).

Iron-induced nephrotoxicity has been observed in both in vitro and in vivo studies (Wu and Qiu 2001; Kadkhodaeem and Gol 2004). In the current work, renal histopathological study showed that glomerular capillaries and medullary vessels are congested mildly in the kidney of Fe group. Also, iron deposition was observed moderately in the cytoplasm of renal tubular cells in the Fe group. Earlier investigations have shown that iron induces oxidative stress (Li et al. 2014). Besides, it has been reported that quercetin has protects against various renal injuries (Erboga et al. 2015; Elbe et al. 2016). Present study showed that quercetin as an antioxidant, by preventing lipid peroxidation, protected the renal injury as was evident from the lowered levels of MDA.

Iron overload is known to result in elevated serum creatinine and BUN (blood urea nitrogen) levels (Kadkhodaeem and Gol 2004). In the current study, FS treatment induced kidney dysfunction in the rats, as was manifested by higher level of $\mathrm{Na}$ fractional excretion $\left(\mathrm{FE}_{\mathrm{Na}}\right)$ and lower level of creatinine clearance $\left(\mathrm{C}_{\mathrm{Cr}}\right)$. The reduction in $\mathrm{C}_{\mathrm{Cr}}$ led to elevation in serum concentration of creatinine and nitrogen urea in Fe group. Furthermore, our results showed the decrease in serum level of total protein in the Fe group. Thus, increased serum nitrogen urea can be attributed to the increase of protein catabolism. Administration of quercetin to FS-treated group prevented these changes, demonstrated by the improvement in the kidney function and the decrease of renal histological alterations. In this regard nephroprotective effect of quercetin against renal damage induced by cisplatin (Ilić et al. 2014) and gentamicin (Abdel-Raheem et al. 2009) through its antioxidative, anti-inflammatory, and anti-apoptotic features is well documented.

\section{Conclusion}

The findings in this study highlighted the protective impact of quercetin against FS-induced toxicity in the liver and kidney. Quercetin exerts its hepato- and nephroprotective effects through binding to iron and reducing the concentration of the catalyzing iron in lipid peroxidation. Since quercetin alone did not induce any biochemical and histopathological changes in the liver and kidney, it should be considered safe as a protective agent in FS-induced hepato- and nephrotoxicity. Nevertheless, further study analyzing quercetin efficacy in the clinical trials should be done.

Acknowledgement. This study was funded by the Research Council of Shiraz University, Shiraz, Iran (grant number 88-GR-SCST-117). The authors would like to thank Dr S.M. Owji for his cooperation in interpreting histopathological data.

Conflict of interest. The authors declare that they have no conflict of interest.

\section{References}

Abdel-Raheem IT, Abdel-Ghany AA, Mohamed GA (2009): Protective effect of quercetin against gentamicin-induced nephrotoxicity in rats. Biol. Pharm. Bull. 32, 61-67 https://doi.org/10.1248/bpb.32.61

Abdel-Raouf N, Ibraheem IB, Abdel-Tawab S, Naser YA (2011): Antimicrobial and anti- hyperlipidemic activities of isolated quercetin from Anabaena aequalis. J. Phycol. 47, 955-962 https://doi.org/10.1111/j.1529-8817.2011.01020.x

Abdel-Reheim MA, Messiha BAS, Abo-Saif AA (2017): Hepatoprotective effect of diosmin on iron-induced liver damage. Int. J. Pharm. 13, 529-540 https://doi.org/10.3923/ijp.2017.529.540

Alleyne M, Horne MK, Miller JL (2008): Individualized treatment for iron-deficiency anemia in adults. Am. J. Med. 121, 943-948 https://doi.org/10.1016/j.amjmed.2008.07.012

Anderson GJ, Frazer DM (2005): Hepatic iron metabolism. Semin. Liver Dis. 25, 420-432 https://doi.org/10.1055/s-2005-923314

Badria FA, Ibrahim AS, Badria AF, Elmarakby AA (2015): Curcumin attenuates iron accumulation and oxidative stress in the liver and spleen of chronic iron-overloaded rats. PLoS One 10, e0134156 https://doi.org/10.1371/journal.pone.0134156

Baliga R, Zhang Z, Baliga M, Shah SV (1996): Evidence for cytochrome P-450 as a source of catalytic iron in myoglobinuric acute renal failure. Kidney Int. 49, 362-369 https://doi.org/10.1038/ki.1996.53

Baliga R, Zhang Z, Baliga M, Ueda N, Shah SV (1998a): In vitro and in vivo evidence suggesting a role for iron in cisplatin-induced nephrotoxicity. Kidney Int. 53, 394-401 https://doi.org/10.1046/j.1523-1755.1998.00767.x

Baliga R, Zhang Z, Baliga M, Ueda N, Shah SV (1998b): Role of cytochrome P-450 as a source of catalytic iron in cisplatininduced nephrotoxicity. Kidney Int. 54, 1562-1569 https://doi.org/10.1046/j.1523-1755.1998.00161.x

Bao D, Wang J, Pang X, Liu H (2017): Protective effect of quercetin against oxidative stress-induced cytotoxicity in rat pheochromocytoma (PC-12) cells. Molecules 22, 1-14 https://doi.org/10.3390/molecules22071122

Bishu K, Agarwal R (2006): Acute injury with intravenous iron and concerns regarding long-term safety. Clin. J. Am. Soc. Nephrol. 1, S19-23

https://doi.org/10.2215/CJN.01420406 
Boadi WY, Iyere PA, Adunyah SE (2003): Effect of quercetin and genistein on copper- and iron-induced lipid peroxidation in methyl linolenate. J. Appl. Toxicol. 23, 363-369 https://doi.org/10.1002/jat.933

Boulton DW, Walle UK, Walle T (1998): Extensive binding of the bioflavonoid quercetin to human plasma proteins. J. Pharm. Pharmacol. 50, 243-249 https://doi.org/10.1111/j.2042-7158.1998.tb06183.x

Bresgen N, Eckl PM (2015): Oxidative stress and the homeodynamics of iron metabolism. Biomolecules 5, 808-847 https://doi.org/10.3390/biom5020808

Cunningham P, Afzal-Ahmed I, Naftalin RJ (2006): Docking studies show that D-glucose and quercetin slide through the transporter GLUT1. J. Biol. Chem. 281, 5797-5803 https://doi.org/10.1074/jbc.M509422200

Das A, Chaudhuri D, Ghate NB, Panja S, Chatterjee A, Mandal N (2015): Protective effect of Clerodendrum colebrookianum leaves against iron-induced oxidative stress and hepatotoxicity in Swiss albino mice. Indian J. Exp. Biol. 53, 281-291

de Vries B, Walter SJ, von Bonsdorff L, Wolfs TG, van Heurn LW, Parkkinen J, Buurman WA (2004): Reduction of circulating redox-active iron by apotransferrin protects against renal ischemia-reperfusion injury. Transplantation 77, 669-675 https://doi.org/10.1097/01.TP.0000115002.28575.E7

Donepudi AC, Ferrell JM, Boehme S, Choi HS, Chiang JYL (2018): Deficiency of cholesterol 7alpha-hydroxylase in bile acid synthesis exacerbates alcohol-induced liver injury in mice. Hepatol. Commun. 2, 99-112 https://doi.org/10.1002/hep4.1129

Dong J, Zhang X, Zhang L, Bian HX, Xu N, Bao B, Liu J (2014): Quercetin reduces obesity-associated ATM infiltration and inflammation in mice: a mechanism including AMPKalpha1/ SIRT1. J. Lipid. Res. 55, 363-374 https://doi.org/10.1194/jlr.M038786

Elbe H, Dogan Z, Taslidere E, Cetin A, Turkoz Y (2016): Beneficial effects of quercetin on renal injury and oxidative stress caused by ciprofloxacin in rats: A histological and biochemical study. Hum. Exp. Toxicol. 35, 276-281 https://doi.org/10.1177/0960327115584686

Erboga M, Aktas C, Erboga ZF, Donmez YB, Gurel A (2015): Quercetin ameliorates methotrexate-induced renal damage, apoptosis and oxidative stress in rats. Ren. Fail. 37, 1492-1497

https://doi.org/10.3109/0886022X.2015.1074521

Fiorani M, Accorsi A, Cantoni O (2003): Human red blood cells as a natural flavonoid reservoir. Free Radic. Res. 37, $331-1338$ https://doi.org/10.1080/10715760310001615998

Gasparin FR, Spitzner FL, Ishii-Iwamoto EL, Bracht A, Constantin J (2003): Actions of quercetin on gluconeogenesis and glycolysis in rat liver. Xenobiotica 33, 903-911 https://doi.org/10.1080/0049825031000140878

Goldstein JL, Brown MS (2009): The LDL receptor. Arterioscler Thromb. Vasc. Biol. 29, 431-438 https://doi.org/10.1161/ATVBAHA.108.179564

MH, Roedig-Penman A (1998): Antioxidant activity of quercetin and myricetin in liposomes. Chem. Phys. Lipids 97, 79-85 https://doi.org/10.1016/S0009-3084(98)00098-X
Heath R, Packer L (1968): Photoperoxidation in isolated chloroplast. I. Kinetics and stoichiometry of fatty acid peroxidation. J. Biochem. Biophs. 125, 189-190 https://doi.org/10.1016/0003-9861(68)90654-1

Hoek-van den Hil EF, van Schothorst EM, van der Stelt I, Swarts HJ, Venema D, Sailer M, Vervoort JJ, Hollman PC, Rietjens IM, Keijer J (2014): Quercetin decreases high-fat diet induced body weight gain and accumulation of hepatic and circulating lipids in mice. Genes Nutr. 9, 418 https://doi.org/10.1007/s12263-014-0418-2

Idilman IS, Akata D, Ozmen MN, Karcaaltincaba M (2016): Different forms of iron accumulation in the liver on MRI. J. Vasc. Interv. Radiol. 22, 22-28

Ilić S, Stojiljković N, Veljković M, Veljković S, Stojanović G (2014): protective effect of quercetin on cisplatin-induced nephrotoxicity in rats. FU. Med. Biol. 16, 71-75

Jung CH, Cho I, Ahn J, Jeon TI, Ha TY (2013): Quercetin reduces high-fat diet-induced fat accumulation in the liver by regulating lipid metabolism genes. Phytotherapy Res. 27, 139-143 https://doi.org/10.1002/ptr.4687

Juźwiak S, Wójcicki J, Mokrzycki K, Marchlewicz M, Białecka M, Wenda-Rózewicka L, Gawrońska-Szklarz B, Droździk M (2005): Effect of quercetin on experimental hyperlipidemia and atherosclerosis in rabbits. Pharmacol. Rep. 57, 604-609

Kadkhodaeem M, Gol A (2004): The role of nitric oxide in ironinduced rat renal injury. Hum. Exp. Toxicol. 23, 533-536 https://doi.org/10.1191/0960327104ht485oa

Kobori M, Masumoto S, Akimoto Y, Oike H (2011): Chronic dietary intake of quercetin alleviates hepatic fat accumulation associated with consumption of a Western-style diet in C57/ BL6 J mice. Mol. Nutr. Food Res. 55, 530-540

https://doi.org/10.1002/mnfr.201000392

Kojima R, Randall JD, Ito E, Manshio H, Suzuki Y, Gullans SR (2004): Regulation of expression of the stress response gene, Osp94: identification of the tonicity response element and intracellular signalling pathways. Biochem. J. 380, 783-794 https://doi.org/10.1042/bj20040313

Lang DR, Racker E (1974): Effects of quercetin and F1 inhibitor on mitochondrial ATPase and energy-linked reactions in submitochondrial particles. Biochim. Biophys. Acta Bioenerg. 333, 180-186 https://doi.org/10.1016/0005-2728(74)90002-4

Leopoldini M, Russo N, Chiodo S, Toscano M (2006): Iron chelation by the powerful antioxidant flavonoid quercetin. J. Agric. Food. Chem. 54, 6343-6351 https://doi.org/10.1021/jf060986h

Li H, Dong B, Park SW, Lee HS, Chen W, Liu J (2009): Hepatocyte nuclear factor 1alpha plays a critical role in PCSK9 gene transcription and regulation by the natural hypocholesterolemic compound berberine. J. Biol. Chem. 284, 28885-28895 https://doi.org/10.1074/jbc.M109.052407

Li Z, Geng YN, Jiang JD, Kong WJ (2014): Antioxidant and anti-inflammatory activities of berberine in the treatment of diabetes mellitus. Evid. Based. Complement. Alternat. Med. 2014, 289264 https://doi.org/10.1155/2014/289264

Lin SY, Wang YY, Chen WY, Chuang YH, Pan PH, Chen CJ (2014): Beneficial effect of quercetin on cholestatic liver injury. J. Nutr. Biochem. 25, 1183-1195 
https://doi.org/10.1016/j.jnutbio.2014.06.003

Madhusudhan KS, Oberoi R (2011): Renal iron deposition in aplastic ane-mia: magnetic resonance imaging appearance. Indian J. Nephrol. 21, 134-135 https://doi.org/10.4103/0971-4065.82145

Mariee AD, Abd-Allah GM, El-Beshbishy HA (2012): Protective effect of dietary flavonoid quercetin against lipemic-oxidative hepatic injury in hypercholesterolemic rats. Pharm. Biol. 50, 1019-1025 https://doi.org/10.3109/13880209.2012.655424

McDonagh T, Macdougall IC (2015): Iron therapy for the treatment of iron deficiency in chronic heart failure: intravenous or oral? Eur. J. Heart Fail. 17, 248-262 https://doi.org/10.1002/ejhf.236

Mladenka P, Macáková K, Filipský T, Zatloukalová L, Jahodár L, Bovicelli P, Silvestri IP, Hrdina R, Saso L. (2011): In vitro analysis of iron chelating activity of flavonoids. J. Inorg. Biochem. 105, 693-701 https://doi.org/10.1016/j.jinorgbio.2011.02.003

Moon J, Lee SM, Do HJ, Cho Y, Chung JH, Shin MJ (2012): Quercetin up-regulates LDL receptor expression in HepG2 cells. Phytother. Res. 26, 1688-1694 https://doi.org/10.1002/ptr.4646

Nocito L, Kleckner AS, Yoo EJ, Jones Iv AR, Liesa M, Corkey BE (2015): The extracellular redox state modulates mitochondrial function, gluconeogenesis, and glycogen synthesis in murine hepatocytes. PLoS One 10, e0122818 https://doi.org/10.1371/journal.pone.0122818

Padma VV, Lalitha G, Shirony NP, Baskaran R (2012): Effect of quercetin against lindane induced alterations in the serum and hepatic tissue lipids in wistar rats. Asian. Pac. J. Trop. Biomed. 2, 910-915 https://doi.org/10.1016/S2221-1691(12)60252-4

Paller MS (1988) Hemoglobin- and myoglobin-induced acute renal failure in rats: role of iron in nephrotoxicity. Am. J. Physiol. 255, F539-544 https://doi.org/10.1152/ajprenal.1988.255.3.F539

Paller MS, Jacob HS (1994): Cytochrome P-450 mediates tissuedamaging hydroxyl radical formation during reoxygenation of the kidney. Proc. Natl. Acad. Sci. USA 91, 7002-7006 https://doi.org/10.1073/pnas.91.15.7002

Papanastasiou DA, Vayenas DV, Vassilopoulos A, Repanti M (2000): Concentration of iron and distribution of iron and transferrin after experimental iron overload in rat tissues in vivo: Study of the liver, the spleen, the central nervous system and other organs. Pathol. Res. Pract. 196, 47-54 https://doi.org/10.1016/S0344-0338(00)80021-7

Pawar N, Nimbalkar V, Gaikvad P (2012): Hepatoprotective activity of a polyherbal mixture in ferrous sulphate and ethanol induced hepatotoxicity experimental animals. Der. Pharmacia Sinica 3, 594-597

Puntarulo S (2005): Iron, oxidative stress and human health. Mol. Aspects. Med. 26, 299-312 https://doi.org/10.1016/j.mam.2005.07.001

Rezaei-Sadabady R, Eidi A, Zarghami A (2016): Intracellular ROS protection efficiency and free radical-scavenging activity of quercetin and quercetin-encapsulated liposomes. Artif. Cells Nanomed. Biotechnol. 44, 128-134 https://doi.org/10.3109/21691401.2014.926456
Rogerio AP, Kanashiro A, Fontanari C, da Silva EVG, LucisanoValim YM, Soares EG, Faccioli LH (2007): Anti-inflammatory activity of quercetin and isoquercitrin in experimental murine allergic asthma. J. Inflamm. Res. 56, 402-408 https://doi.org/10.1007/s00011-007-7005-6

Rui L (2014): Energy metabolism in the liver. Compr. Physiol. 4, $177-197$ https://doi.org/10.1002/cphy.c130024

Sarkar R, Hazra B, Mandal N (2015): Amelioration of iron overload-induced liver toxicity by a potent antioxidant and iron chelator, Emblica officinalis Gaertn. Toxicol. Ind. Health 31, 656-669 https://doi.org/10.1177/0748233713483195

Singh S, Singh SK, Kumar M, Chandra K, Singh R (2011): Ameliorative potential of quercetin against paracetamol-induced oxidative stress in mice blood. Toxicol. Int. 18, 140-145 https://doi.org/10.4103/0971-6580.84267

Smith CP, Thevenod F (2009): Iron transport and the kidney. Biochim. Biophys. Acta 1790, 724-730 https://doi.org/10.1016/j.bbagen.2008.10.010

Strobel P, Allard C, Perez-Acle T, Calderon R, Aldunate R, Leighton F (2005): Myricetin, quercetin and catechin-gallate inhibit glucose uptake in isolated rat adipocytes. Biochem. J. 386, 471-478 https://doi.org/10.1042/BJ20040703

Sudhir V, Shah MD (2001): Role of iron in progressive renal disease. Am. J. Kidney Dis. 37, S30-33 https://doi.org/10.1053/ajkd.2001.20736

Thévenod F, Wolff NA (2016): Iron transport in the kidney: implications for physiology and cadmium nephrotoxicity. Metallomics 8, 17-42 https://doi.org/10.1039/C5MT00215J

Vlachodimitropoulou E, Sharp PA, Naftalin RJ (2011): Quercetiniron chelates are transported via glucose transporters. Free Radic. Biol. Med. 50, 934-944 https://doi.org/10.1016/j.freeradbiomed.2011.01.005

Wang LL, Zhang ZC, Hassan W, Li Y, Liu J, Shang J (2015): Amelioration of free fatty acid-induced fatty liver by quercetin-3-O- $\beta$-D-glucuronide through modulation of peroxisome proliferator-activated receptor-alpha/sterol regulatory element-binding protein-1c signaling. Hepatol. Res. 46, 225-238 https://doi.org/10.1111/hepr.12557

Wu Z, Qiu L (2001): Effect of nitric oxide on iron-mediated cytotoxicity in primary cultured renal proximal tubules. Cell Biochem. Funct. 19, 237-247

https://doi.org/10.1002/cbf.921

Zager RA, Johnson AC, Hanson SY, Wasse H (2002): Parenteral iron formulations: A comparative toxicologic analysis and mechanisms of cell injury. Am. J. Kidney Dis. 40, 90-103 https://doi.org/10.1053/ajkd.2002.33917

Zarjou A, Bolisetty S, Joseph R, Traylor A, Apostolov EO, Arosio P, Balla J, Verlander J, Darshan D, Kuhn LC, Agarwal A (2013): Proximal tubule $\mathrm{H}$-ferritin mediates iron trafficking in acute kidney injury. J. Clin. Invest. 123, 4423-4434 https://doi.org/10.1172/JCI67867

Zhang Z, Lian B, Cui F (2008): Effect of FeSO4 treatment on glucose metabolism in diabetic rats. Biometals 21, 685-691 
https://doi.org/10.1007/s10534-008-9153-8

Zhang Y, Gao Z, Liu J, Xu Z (2011): Protective effects of baicalin and quercetin on an iron-overloaded mouse: comparison of liver, kidney and heart tissues. Nat. Prod. Res. 25, 1150-1160 https://doi.org/10.1080/14786419.2010.495070

Zhang M, Xie Z, Gao W, Pu L, Wei J, Guo C (2016): Quercetin regulates hepatic cholesterol metabolism by promoting cho- lesterol-to-bile acid conversion and cholesterol efflux in rats. Nutr. Res. 36, 271-279

https://doi.org/10.1016/j.nutres.2015.11.019

Received: June 30, 2018

Final version accepted: September 14, 2018

First published online: January 18, 2019 